\title{
A Fuzzy AHP Approach to Compare Transit System Performance in US Urbanized Areas
}

\author{
Xin Li, Ph.D. \\ University of Wisconsin-Milwaukee \\ Yingling Fan, Ph.D. \\ University of Minnesota \\ John W. Shaw, P.E. \\ University of Wisconsin-Madison \\ Yunlei Qi \\ University of Minnesota
}

\begin{abstract}
Public transit systems in the United States often face multiple policy objectives. Typically, stakeholders desire frequent service on an extensive network, but funding and other resources are constrained, creating complicated relationships between service effectiveness goals and business efficiency goals. Using data from the National Transit Map (NTM), this study evaluated the general performance of transit systems across 294 Urbanized Areas (UZAs) in the US, which were stratified into six peer groups based on population. Transit efficiency and effectiveness were compared by developing a composite business efficiency index score and a composite service effectiveness index score for each urbanized area. The scores were generated using a fuzzy logic extension of the Analytical Hierarchy Process (AHP), which allows automated weighting of the measures. The NTM currently includes a limited set of performance measures, and each transit agency's data are associated with the largest urban area it serves; consequently, it is perhaps best-suited for identifying highperforming UZAs and less suitable for identifying the weakest performers. The analytical results suggest that a few UZAs (mainly densely-populated cities and university towns) are simultaneously able to achieve high scores on both business efficiency and service effectiveness. In most small- and medium-size conurbations, business efficiency appears to be a higher policy priority than service effectiveness.
\end{abstract}

Keywords: Performance evaluation, US urban transit system, efficiency and effectiveness, fuzzy AHP 


\section{Introduction}

Public transit providers in the US are a unique category of organizations that blend some characteristics of private-sector businesses with some characteristics of public agencies. Managers and policymakers involved in transit typically need to strike a balance among at least three competing perspectives or sets of objectives:

- Perspective 1: Transit is a business that needs to meet customer expectations while using personnel, equipment, and financial resources efficiently.

- Perspective 2: Transit is a social service that provides essential mobility for non-drivers, people with disabilities, and other socially- and economicallydisadvantaged people.

- Perspective 3: Transit is a policy intervention that might help relieve traffic congestion, reduce energy consumption, diminish pollutant emissions, promote compact urban form, and/or stimulate revitalization of distressed areas.

These objectives often conflict, so it is necessary to strike a balance between business efficiency and service effectiveness, which were defined by Fielding et al. (1985) and Chu and Fielding (1990):

Business efficiency is a statement about the achievements of an agency in transforming a set of inputs into a set of outputs. For example, can existing levels of transit ridership be obtained with less equipment or fewer operational resources? Can increased services generate more fare box revenue? Service effectiveness reflects the ability of transit operations to meet certain goals. Do the services attract a significant number of users or transit-dependent populations from a given level of input?

Often, there are perceived trade-offs between efficiency and effectiveness. For example, assuring that there is basic mobility for non-drivers throughout an urban area implies that a transit system will need to provide a considerable amount of service in areas with relatively low demand, which could drive down measures of operational and financial efficiency.

Performance measurement and benchmarking tools provide opportunities for transit system managers to clarify the links between policy decisions and system performance outcomes. For example, a carefully-chosen set of performance measures could assist in balancing (or re-balancing) conflicting objectives that affect both strategic long-range planning and tactical day-to-day decisionmaking. Moreover, performance evaluation can contribute to better understanding of the relationships between efficiency and effectiveness.

Transit Cooperative Research Program (TCRP) Report 141 (Ryus et al. 2010) suggests a performance evaluation process that begins by hand-selecting a peer group with similar characteristics and then computing cross-comparison metrics using publicly-available data sets or information obtained directly from the peer agencies. In this study, we compared transit performance at the urbanized area (UZA) level. As defined by the US Census, each UZA is a contiguous urban region with a population greater than 50,000 . 
For this analysis, UZAs from the 2010 Census were first stratified into six groups based on population, as shown in Table 1. The implicit assumption is that transit resources and objectives are somewhat comparable within these groups. Next, a Fuzzy Analytical Hierarchy Process (Fuzzy AHP) model was used to determine how similar certain transit performance measures are within each group and compare the efficiency performance and effectiveness performance by generating a business efficiency index score and a service effectiveness index score for each urbanized area, along with composite scores that include both efficiency and effectiveness measures for all UZAs within each of the six peer groups. The fuzzy-AHP approach includes an automated process to weigh individual performance criteria, which avoids subjectivity in the weighting and scoring process.

TABLE 1.

Peer Groups Used for This Analysis

\begin{tabular}{|c|c|c|c|c|c|}
\hline $\begin{array}{c}\text { Peer } \\
\text { Group }\end{array}$ & $\begin{array}{c}\text { Urbanized Area } \\
\text { (UZA) Population }\end{array}$ & $\begin{array}{c}\text { Number } \\
\text { of Census } \\
\text { UZAs }\end{array}$ & $\begin{array}{c}\text { Total } \\
\text { Population of } \\
\text { Census UZAs }\end{array}$ & $\begin{array}{c}\text { Number } \\
\text { of UZAs in } \\
\text { This Study }\end{array}$ & $\begin{array}{c}\text { Total } \\
\text { Population of } \\
\text { NTM UZAs }\end{array}$ \\
\hline A & $>2.5$ million & 16 & 93 million & 16 & 93 million \\
\hline B & $1-2.5$ million & 26 & 43 million & 26 & 43 million \\
\hline C & $500,000-1$ million & 38 & 27 million & 36 & 26 million \\
\hline D & $250,000-500,000$ & 69 & 23 million & 62 & 21 million \\
\hline E & $100,000-250,000$ & 149 & 23 million & 94 & 15 million \\
\hline F & $50,000-100,000$ & 199 & 14 million & 60 & 5 million \\
\hline
\end{tabular}

Transit performance characteristics for each UZA were obtained from the National Transit Map (NTM), a data set recently developed by other researchers on behalf of the Federal Transit Administration (FTA). It is important to acknowledge an important characteristic of the NTM at the outset: transit operators that serve more than one UZA (or serve an UZA and adjoining rural areas) are mapped exclusively to the largest UZA they serve. This characteristic has the potential to overstate (to a degree) the amount of service identified as being provided in large UZAs and understate the amount of service provided in small UZAs. It is also important to note that many Census 2010 UZAs have very irregular boundaries, which do not necessarily coincide with municipal boundaries or transit service area boundaries.

\section{Literature Review}

Transit system performance evaluation is an important task for transit service providers seeking to respond to passenger demand trends, operational constraints, stakeholder concerns, and changing service needs. It allows system managers to achieve better economic performance assessment, organizational administration, transit planning, and financial management. Its importance has been increasingly realized by oversight authorities, transit agencies, and groups representing passengers, major employers, and other stakeholders. Thus, assessing transit system performance has been one of the most widely investigated areas of research within the transit industry. 
Fielding et al. (1978) carefully described nine performance indicators for transit management, among which Revenue Vehicle Hours per Employee, Revenue Vehicle Hours per Vehicle and Operating Expense per Revenue Vehicle Hour were regarded as indicators of efficiency; Revenue Passengers per Service Area Population, Percent of Population Served, Total Passengers per Vehicle, and Revenue Passengers per Revenue Vehicle Hour were used as effectiveness indicators; and Operating Expenses per Total Passenger and Operating Expense per Revenue Passenger were chosen for overall performance evaluation. Several years later, Fielding et al. (1985) used FY 1980 Section 15 data to identify a set of performance indicators using factor analysis. The selected indicators were also used to evaluate the performance of fixed routes.

When the application of Data Envelopment Analysis (DEA) began to become more widely used for system efficiency assessment, Chu et al. (1990) and Karlaftis (2004) applied the approach to evaluating efficiency and effectiveness of transit systems. To document the state of transit performance evaluation in the US, Fielding (1992) examined three programs (Federal triennial review, California performance audits, and Los Angeles program) in terms of four components: dimensions for policy objectives, indicators, information systems, and incentives.

Some of the previously-published research on transit performance evaluation focuses on the service level. These studies include user perception- (customer satisfaction-) based approaches, efficiency indicator-based approaches, and approaches that combine both user opinions and efficiency indicators (Abreha 2007; Badami and Haider 2007; Sheth et al. 2007; Nathanail 2008; Tyrinopoulos and Antoniou 2008; Lao and Liu 2009; Eboli and Mazzulla 2011).

To monitor transit system performance and support public transport development, some transit associations and organizations have developed efficiency assessment indicators and related agency guidance. For example, the International Association of Public Transport (known by its French-language initials, UITP) has suggested a group of indictors to compare public transport system performance across cities and regions. The indicators suggested by UITP include the population of transit users; the service coverage; and the number of bus routes, stations, etc. (UTIP 2011). The Transportation Research Board's Transit Capacity and Quality of Service Manual (TCQSM) (TRB 2003) includes guidelines for evaluating the performance of public transport systems using a three-level evaluation index system: station, route, and system. Other resources, such as the annual American Public Transportation Association (APTA) Public Transportation Fact Book (Neff and Dickens 2013) provide extensive statistical data about resource inputs and production outputs for each agency, but offer only limited interpretive advice.

With support from FTA, TCRP Report 88 was published, a guidebook for developing a transit performance-measurement system (Kittelson \& Associates, Inc. et al. 2003). The guidebook offers technical assistance and suggestions on how to implement and use performance measurement on an ongoing basis at a transit agency. It suggests a wide range of performance measure categories, including availability, service delivery, community, travel time, safety and security, maintenance and construction, economic, 
capacity, paratransit, and comfort. Measures based on these categories can be grouped into four general types: individual measures, ratios, and indices and level-of-service indicators. The report also includes 12 domestic and international case studies such as Livermore, CA; Denver, CO; and Sydney, Australia. TCRP Report 141 (Ryus et al. 2010) also focuses on transit performance evaluation and highlights the importance of the peer compassion approach. The report suggests that peer-grouping and performance measurement should serve as a starting point for a transit agency to ask questions about performance and identify improvement opportunities.

In addition to the abundant studies evaluating the general performance of transit systems, some scholars have concentrated specifically on investigating the relationship between efficiency performance and effectiveness performance, sometimes claiming that these two objectives are mutually exclusive (Griffis et al. 2004). Other studies suggest that treating efficiency and effectiveness as a dichotomy is unwarranted. For example, Talley and Anderson (1981) explored the relationship between transit efficiency and effectiveness from the perspective of the bus company itself and in terms of government objectives for transit service. They argued that from the point of view of the transit firm, the aim is to maximize ridership within allowable deficit limits as well as minimize the operating costs to maintain a certain service level. They also argue that the government or public policy objectives for transit can be defined as maximizing social well-being, economic development, and environmental quality. Therefore, attainment of these objectives is predicated on the transit agency being both effective and efficient, and they should not be treated as mutually exclusive. Similar findings were presented by Karlaftis in 2004 using Data Envelopment Analysis (DEA) to analyze the relationship between transit system efficiency and effectiveness. Using data from 256 US transit systems over a five-year period, he found that efficiency and effectiveness were positively related - that is, the most efficient systems were also the most effective.

Together, the two TCRP reports and various journal articles on transit performance evaluation make many valuable contributions toward developing transit performancemeasurement systems, but there are major limitations:

- Both TCRP reports suggest a wide range of measures that impact transit system performance but leave many details unresolved, such as how to weigh dissimilar criteria.

- Most studies have focused on measuring performance at the operator or agencylevel, usually concentrating on service level. There is lack of a comprehensive performance evaluation and comparison at other spatial scales, such as cities and urbanized regions. Importantly, many US urbanized areas have multiple transit service providers. For example, buses and commuter rail often are operated by different entities. Although numerous UZAs span more than one county or state, transit agencies in some of these UZAs are not authorized to cross jurisdictional boundaries. From the perspective of transit riders, the most important issue is the overall quality of transit service available in a city or urban region. Comparisons at the transit agency/provider level are less relevant to transit users, particularly 
since many operators have made efforts to integrate their routes, schedules, and fare payment systems.

- Although Karlaftis (2004) concluded that efficiency and effectiveness are positively related using NTD data (1990-1994), the theoretical limitations of DEA models are a critical issue, and the analysis is based on a data set that is now more than 20 years old. Many empirical studies have clearly identified major limitations of applying DEA models in efficiency assessment. For example, DEA evaluates the relative efficiency of decisionmaking units but does not allow for ranking of the efficient units themselves (Charnes et al. 1978; Andersen and Christian 1993; Cook and Seiford 2009). Further, some statisticians and economists have stated that DEA will lead to the deviation of efficiency evaluation when the number of samples is small (Korostelev et al. 1995; Simar and Wilson 1998; Song et al. 2013).

In addition to the TCRP reports and scholarly works, the US mass media has shown interest in transit performance evaluation. For example, in 2011, US News \& World Report ranked the "10 Best Cities for Public Transportation" as follows: Denver-Aurora, CO.; New York-Newark, NY-NJ-CT.; Los Angeles-Long Beach-Santa Ana, CA.; Boston, MA-NH-Rl; Portland, OR: San Jose, CA; Salt Lake City, UT; San Diego, CA; Seattle, WA; and Honolulu, HI. Unfortunately, it provided relatively few details about the ranking methodology. In addition, there was a discrepancy between the headline ("Best Cities") and the ranking method (metropolitan areas). In some cases, the rankings seem to violate the principle of peer-group comparison suggested by TCRP Report 141—some of the cities differ considerably in terms of population, transit system size, and other basic characteristics.

\section{Scope of This Analysis}

The main objective of this research was to assess the relative importance of various performance measures in distinguishing transit performance within the six city peer groups identified in Table 1 and how well individual agencies perform relative to peerdefined norms. The study focused on the following research tasks:

1. Implement an extended AHP with the integration of fuzzy logic to evaluate overall performance for each peer group at UZA level. In essence, this is a software-driven process that mathematically establishes weighting criteria for each performance measure (or objective), ranks the peer group members on each individual performance measure, and produces an overall weighted ranking. In contrast to most other multi-criteria ranking systems, Fuzzy AHP makes no $a$ priori judgments about the importance of the individual performance measures. This removes some of the subjectivity associated with traditional methods for establishing weighting criteria, such as analyst judgment or smallgroup consensus. The proposed approach offers the advantage of avoiding the uncertainty and potential lack of repeatability that can affect the assignment of weighting criteria by individual people or expert panels. 
2. Develop a specific comparison of efficiency and effectiveness by generating both a composite business efficiency index score and a composite service effectiveness index score for each urbanized area to explore the relationship between efficiency and effectiveness in all peer population groups.

Note that the general purpose of this study was simply to demonstrate how the fuzzy AHP methodology can be applied to transit analysis. Given the limitations of the input data set, it is important to state clearly that the authors did not intend this demonstration to be interpreted as a definitive statement that "transit system $X$ is better than transit systems $Y$ and $Z$." Although a multi-city analysis was used to demonstrate the methodology, if appropriate data was available, a similar methodology could potentially be applied to an internal analysis of operational entities within a transit system-for example, treating collections of bus routes or commuter rail lines as the peer groups.

\section{Data and Data Limitations}

Data for this study came from the National Transit Map (NTM) developed at the University of Minnesota, which aggregates agency-level performance data from the 2013 National Transit Database (NTD) to the UZA level. In contrast to the agencylevel information provided in some other US transit data sources, the NTM combines the data for all operators serving an UZA. For example, the Chicago UZA has four main transit operators (Chicago Transit Authority, Metra, Pace, and Northern Indiana Commuter Transportation District), and the NTM combines their data to facilitate comparison of the Chicago UZA's performance with other American UZAs. A very important characteristic of the NTM data set is that to avoid double-counting in summary statistics, the NTM associates each transit operator with only one UZA, specifically the most-populous UZA served by that operator. Thus, services that link two or more UZAs (or an UZA and adjoining rural areas) appear in the NTM only as part of the more populous UZA (Fan 2015).

A total of 497 UZAs were defined by the 2010 US Census (486 in the US proper and 11 in Puerto Rico) (US Census Bureau 2013). Of these, 294 are free of missing values for the performance measures used in this study, as shown in Table 1. Many of UZAs that have missing data did not report statistical data to FTA (Fan 2015). A few urbanized areas were removed from the evaluation list due to incomplete data; for example, Atlantic City, NJ, is missing data for two of the performance measures. The locations of the cities that were analyzed are shown in Figure 1. The majority of UZAs that were not included in this study are in the smaller UZA groups (especially Peer Groups E \& F). 


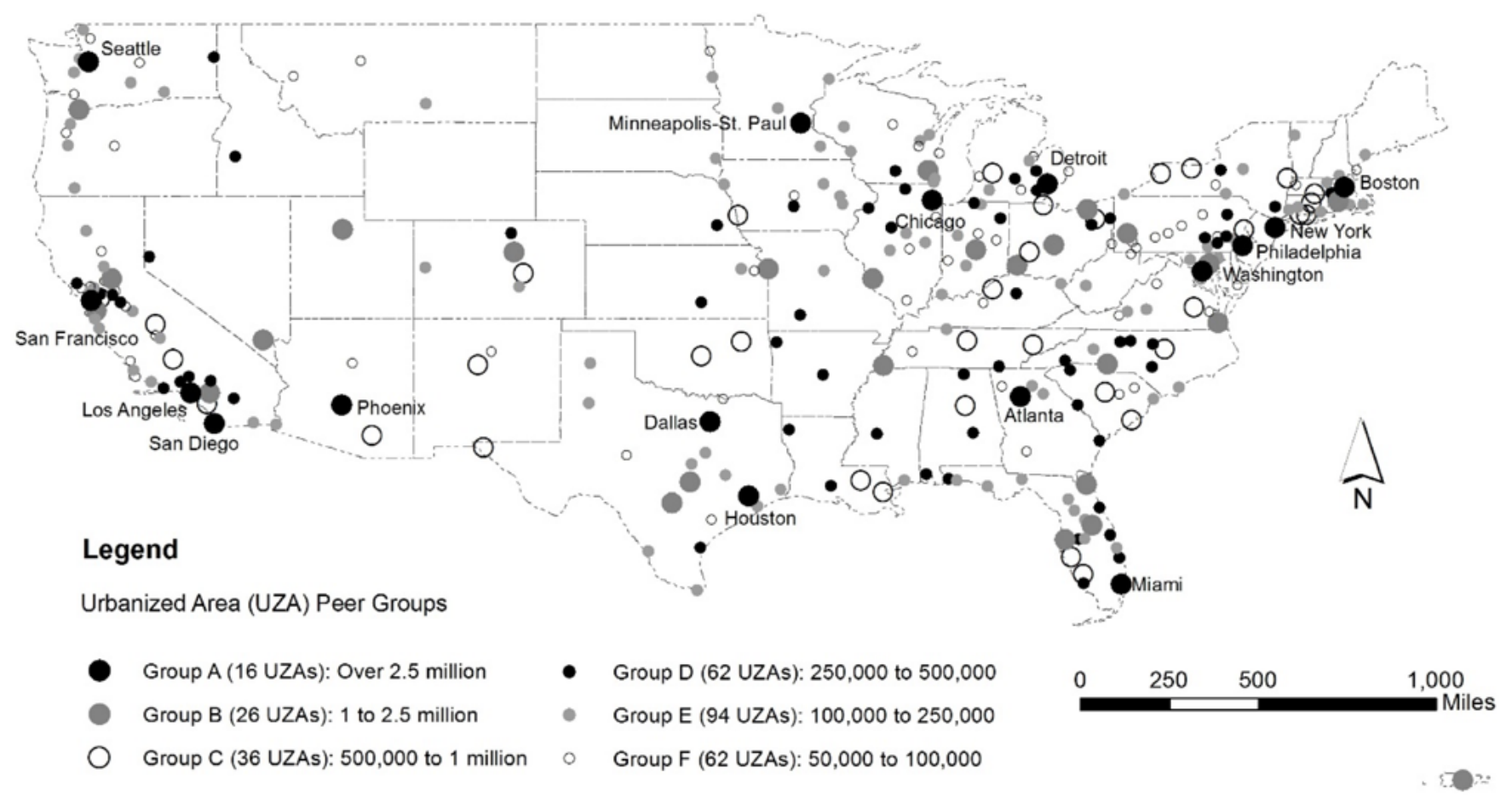

FIGURE 1. Geographic distribution of cities included in analysis

Since each transit operator's services are attributed to the largest UZA it serves, some UZAs that are served by transit do not appear in the NTM listings. For example, Round Lake Beach, IL (a Peer Group D UZA) is served by Metra trains and Pace buses that would be reported as part of the Chicago data. Continuing this Chicago-area example, the commuter rail service provided by the Northern Indiana Commuter Transportation District (operator of the 90-mile South Shore Line from Chicago to South Bend, IN) is attributed to the Chicago UZA and not to South Bend (another Group D UZA) nor to any of the rural communities along the route. As a result, the South Bend area's scores are based on its local bus systems and exclude the commuter rail service.

Since the NTM attributes cross-UZA services only to the largest UZA, the amount of transit service available to smaller communities is understated in some cases. This issue could potentially be addressed by pro-rating the NTM data to adjust for cross-UZA services. Due to the highly irregular boundaries of most Census-defined UZAs, this would require an in-depth analysis based on route-level (or stop-level) data, perhaps also factoring in service frequency. Since the primary purpose of this study was to probe the feasibility of using a fuzzy AHP analytical approach with a national transit data set, undertaking such an analysis was beyond the scope of the work described here, and the results should be interpreted accordingly. 


\section{Performance Measure Criteria}

As shown in Table 2, five transit performance measures are currently included in the NTM database. Therefore, our demonstration analysis was based only on these metrics.

TABLE 2.

Service Characteristics Used for This Analysis

\begin{tabular}{|l|l|l|}
\hline \multicolumn{1}{|c|}{ Code } & \multicolumn{1}{c|}{ Characteristic } & \multicolumn{1}{c|}{ Normalization Divisor } \\
\hline VOMS & Vehicles operated in maximum service & Unlinked passenger trips \\
\hline FRE & Fare revenues earned & Vehicle revenue miles \\
\hline VRM & Vehicle revenue miles & UZA land area \\
\hline UPT & Unlinked passenger trips & UZA population \\
\hline TWM & Length of transit way system & UZA land area \\
\hline
\end{tabular}

All urbanized areas were scored based on the combined totals for the eight NTM transport modes (bus, bus rapid transit [BRT], commuter rail, heavy rail, light rail, street car, other rail, and other non-rail). The detailed definitions of the criteria are further defined by NTM project (Fan 2015), as follows:

- Vehicles Operated in Maximum Service (VOMS) - the revenue vehicle count taken during a transit agency's maximum season of the year, on the day of the week that this maximum occurs; not taken on a day when a special event or other extreme set of circumstances would cause the resulting tally to represent a onetime event rather than a recurring maximum service requirement.

- Fare Revenue Earned (FRE) - all income received directly from passengers, paid either in cash or through pre-paid tickets, passes, etc.; includes donations from those passengers who donate money on the vehicle and reduced fares paid by passengers in a user-side subsidy arrangement.

- Vehicle Revenue Miles (VRM) - miles that vehicles travel while in revenue service; excludes miles that vehicles travel for deadhead services (leaving or returning to the garage or yard facility, changing routes, or when there is no expectation of carrying revenue passengers), operator training, maintenance testing, and school bus and charter services.

- Unlinked Passenger Trips (UPT) - number of passengers who board public transportation vehicles; passengers are counted each time they board vehicles no matter how many vehicles they use to travel from their origin to their destination.

- Transit Way Mileage (TWM) - length of transitway system; NTD's transitway mileages include all fixed-route and fixed-schedule modes (i.e., track mileage for rail modes and lane/route miles for fixed-route and fixed-schedule non-rail modes).

To reduce scaling bias, all five criteria were normalized for each of the 294 UZAs. The normalization method was as follows:

- Fare Revenue Earned (FRE) was divided by Vehicle Revenue Miles (VRM) to obtain the fare income per revenue-mile operated. 
- Vehicle Revenue Miles (VRM) was divided by the UZA's land area to provide an indicator of the operational intensity of the transit service.

- Unlinked Passenger Trips (UPT) was divided by Vehicles Operated in Maximum Service (VOMS) to provide a rough indicator of fleet utilization efficiency.

- Unlinked Passenger Trips (UPT) was divided by the UZA's population to serve as a rough indicator of the extent to which residents use transit.

- Transitway Mileage (TWM) was divided by the UZA's land area to provide an indicator of the area's transit network density.

\section{Fuzzy AHP Evaluation Method}

AHP is a biased multi-criteria decisionmaking process introduced by Saaty (1980) and subsequently used in several transportation system evaluation studies. For example, Yeh et al. (2000) employed a fuzzy multi-criteria analysis approach to evaluate the performance of urban public transport systems, and Hanaoka and Kunadhamraks (2009) used a fuzzy logic AHP to evaluate the logistics performance of intermodal freight transportation. Yu et al. (2011) developed a comprehensive AHP-based framework for ranking candidate location plans of multiple urban transit hubs. Li et al. (2015) proposed an enhanced fuzzy AHP approach to evaluate, monitor, and compare the development of public transportation systems towards transit metropolis status in different cities in China, in which two levels-policy and technical-were integrated into one framework.

AHP allows decisionmakers to decompose a complex problem into three hierarchical levels - goal, criteria, and alternatives. Three critical issues can arise when applying conventional AHP:

- How to handle criteria weighting when the judgment scale is very unbalanced.

- How to construct the pair-wise comparison matrix properly, given the potential for variability in the selection, judgment, and preferences of human decisionmakers.

- How to obtain a completely consistent pair-wise comparison matrix that satisfies the consistency-check rules.

To remedy these deficiencies in the structure of conventional AHP and limit the risk that judgment variations could result an unreliable analysis, an enhanced fuzzy AHP model was developed by Li et al. (2015). The advantages of the proposed fuzzy AHP structure lie in its ability to:

- Normalize the scales of different technical indicators.

- Construct a matrix of pair-wise comparisons using a fuzzy set.

- Optimize the weight of each criterion (using a non-linear programming model to maximize the judgment consistency). 
The use of a fuzzy analytical model for weighting the technical criteria moves toward an evaluation method that is less dependent on human judgment and allows identification of transit system strengths and weaknesses with respect to each specific performance measure. To facilitate the model presentation, all definitions and notation used hereafter are summarized in Table 3.

TABLE 3.

Notation of Key Parameters Used in Proposed Model

\begin{tabular}{|l|l|}
\hline$i$ & Index corresponding to criteria $(i=1 \ldots n)$ \\
\hline$k$ & Index corresponding to cities to be evaluated $(k=1 \ldots m)$ \\
\hline$x_{i k}$ & Indicator representing the selected city $k$ being evaluated by criterion $i$ \\
\hline$\mu_{i k}$ & Fuzzy membership value corresponding to indicator $x_{i k}$ \\
\hline$\mu_{i}$ & Average fuzzy membership value for criterion $i$ \\
\hline$x_{i(\min )}$ & Minimal crisp value for criterion $i$ \\
\hline$x_{i(\max )}$ & Maximal crisp value for criterion $i$ \\
\hline$s_{i}$ & Standard deviation of indicator values corresponding to criterion $i$ \\
\hline$s_{\text {min }}$ & min $\left\{s_{i} \mid i=1, \ldots, n\right\}$ \\
\hline$s_{m a x}$ & max $\left\{s_{i} \mid i=1, \ldots, n\right\}$ \\
\hline$A=\left(a_{i j}\right)_{n x n}$ & Pair-wise comparison matrix \\
\hline$a_{m}$ & Comparison scale for the pair-wise comparison matrix \\
\hline$w_{i}$ & Weight for the policy criterion $i$ \\
\hline$Y=\left(y_{i j}\right)_{n x n}$ & Consistency judgment matrix \\
\hline$C I C(n)$ & Consistency index coefficient \\
\hline$s_{k}$ & Synthesized evaluation score of city $k$ \\
\hline
\end{tabular}

Details about the fuzzy AHP approach can be found in Li et al. (2015). The procedure can be summarized as follows.

\section{Step 1: Fuzzy Scaling}

Two types of indicators, i.e., "the-lower-the-better" and "the-higher-the-better," are identified to normalize $x_{i k}$ with their fuzzy sets, given by:

- For the lower-the-better indicators:

$\mu_{i k}=\frac{\left[x_{i(\max )}+x_{i(\min )}-x_{i k}\right]}{\left[x_{i(\max )}+x_{i(\min )}\right]}$

- For the higher-the-better indicators:

$$
\mu_{i k}=\frac{x_{i k}}{\left[x_{i(\max )}+x_{i(\min )}\right]}
$$




\section{Step 2: Pair-Wise Comparisons}

Using the standard deviation of indicators determines which criterion is more important and to what extent.

$$
s_{i}=\sqrt{\sum_{k=1}^{m}\left(\mu_{i k}-\overline{\mu_{l}}\right)^{2} /(m-1)} \quad i=1 \ldots n
$$

Then, a pair-wise comparison matrix $A=\left(a_{i j}\right)_{n x n}$ is created to measure the relative importance of criterion $i$ over criterion $j$, given by:

$$
\begin{array}{ll}
a_{i j}=\frac{s_{i}-s_{j}}{s_{\max }-s_{\min }} \times\left(a_{m}-1\right)+1 & s_{i} \geq s_{j} \\
a_{i j}=\frac{1}{\left[\frac{s_{j}-s_{i}}{s_{\max }-s_{\min }} \times\left(a_{m}-1\right)+1\right]} & s_{i} \leq s_{j}
\end{array}
$$

where $a_{m}=\min \left\{9, \operatorname{int}\left(\frac{s_{\max }}{s_{\min }}+0.5\right)\right\}$ is a comparison scale (range from 1 to 9) for all criteria as recommended by jin et al. (2004).

\section{Step 3: Weight Determination}

According to AHP analysis theory, a consistency-check of a pair-wise matrix is required to correctly reflect the importance of criterion $j$ over criterion $i$. However, as mentioned in many previous studies (Bryson 1995; Jin et al. 2004; Saaty 1980; Sudhakar and Shrestha 2003; Yu 2002), it is usually difficult in practice to obtain a completely consistent pair-wise comparison matrix. Thus, this study proposed the following nonlinear optimization model to estimate the weights $\left\{w_{i} \mid i=1 \ldots n\right\}$ from the inconsistent $a_{i j}$ :

$$
\begin{aligned}
& \min \operatorname{CIC}(n)=\sum_{i=1}^{n} \sum_{j=1}^{n} \frac{\left|y_{i j}-a_{i j}\right|}{n^{2}}+\sum_{k=1}^{m} \sum_{l=1}^{m} \frac{\left|y_{i j} w_{j}-w_{i}\right|}{n^{2}} \\
& y_{i i}=1, i=1 \cdots n \\
& \frac{1}{y_{j i}}=y_{i j} \in\left|a_{i j}-d a_{i j}, a_{i j}+d a_{i j}\right|(i=1, \ldots, n, j=i+1, \ldots, n) \\
& w_{i}>0, i=1 \ldots n \\
& \sum_{i=1}^{n} w_{i}=1
\end{aligned}
$$

In the above equations, $Y=\left(y_{i j}\right)_{n x n}$ is defined as the consistency judgment matrix, which is adjusted based on $A=\left(a_{i j}\right)_{n x n}$ during the minimizing process of the consistency index coefficient, denoted by $C I C(n)$. Based on extensive numerical 
experiments this study has employed the convergence criterion $C I C(n) \leq 0.1$ to ensure that the resulting judgment matrix $Y=\left(y_{i j}\right)_{n x n}$ is consistent.

\section{Step 4: Synthesis}

After obtaining the weights for all criteria from the optimization model, the final ranking score of each city $k$ will be synthesized by equation (11), which can be stated as:

$$
s_{k}=\sum_{i=1}^{n} \mu_{i k} * w_{i}
$$

The synthesis results will reflect the overall performance for all the areas with respect to the selected criteria.

\section{Evaluation Process}

Two types of evaluation were completed for this study. The first is an overall composite ranking for each of the six peer groups. The second compares efficiency and effectiveness metrics for each group. In the first objective, five normalized indicatorsFRE/VRM, VRM/LandArea, UPT/VOMS, UPT/Population, and TWM/LandArea-were taken into consideration in the evaluation process. For the second analysis, two indices were generated: one represents business efficiency, including fare revenue per revenue mile (FRE/VRM) and operating vehicle utilization (UPT/VOMS); the second represents service effectiveness, including unlinked trips per capita (UPT/Population) and service coverage (VRM/LandArea).

When computing overall composite ratings, the proposed model estimates the weights for each of the five criteria independently for each peer group. For the purpose of comparing efficiency and effectiveness, the model is used to measure the relative importance between the two indicators for the "efficiency group" and the "effectiveness group." After the weights were computed, the ranking scores were synthesized using equation (14) for both objectives.

\section{Analysis Results}

\section{Overall Composite Ranking}

Composite scores for each of the six peer groups (combining both business efficiency and operational effectiveness measures) are presented in Figure 2, Table 4, and Table 5. Figure 2 shows a complete ranking for Group A (although this group includes only 16 UZAs, it represents close to a third of the total US population). Table 4 provides complete results for Group B, including detailed results for all five metrics as well as the final synthesis and rankings. Due to space constraints, Table 5 for Groups $C-F$ is abbreviated to include only the UZAs rankings in the top 10 and bottom 10 of each peer group. 


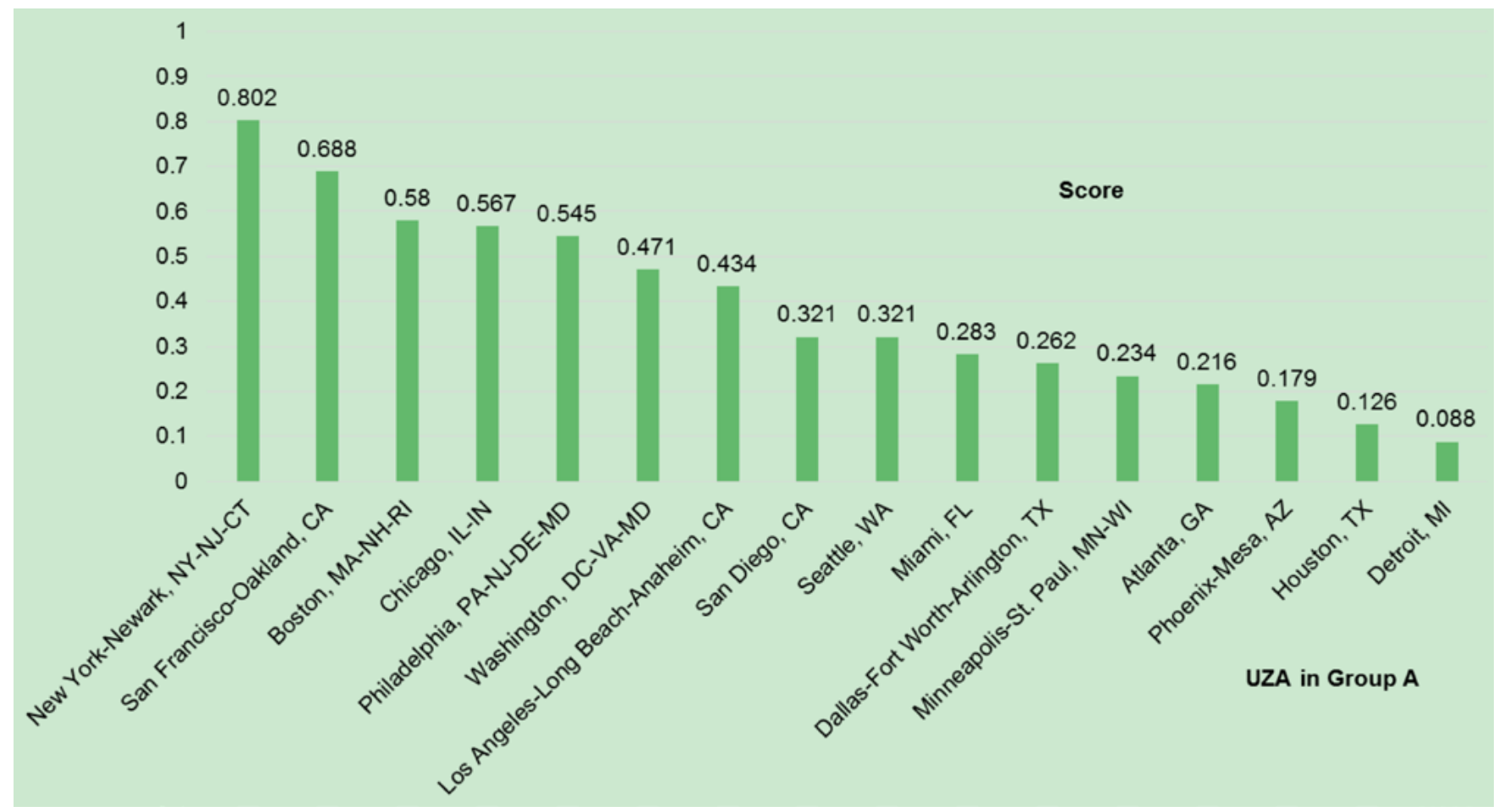

FIGURE 2. Group A composite ranking

TABLE 4. Analytical Results for Group B

\begin{tabular}{|l|c|c|c|c|c|c|c|}
\multicolumn{1}{|c|}{ UZA } & $\begin{array}{c}\text { VOMS/ } \\
\text { UPT }\end{array}$ & $\begin{array}{c}\text { FRE/ } \\
\text { VRM }\end{array}$ & $\begin{array}{c}\text { VRM/ } \\
\text { LandArea }\end{array}$ & UPT/POP & $\begin{array}{c}\text { TWM/ } \\
\text { LandArea }\end{array}$ & Synthesis & Ranking \\
\hline Salt Lake City-West Valley City, UT & 0.0683 & 0.0654 & 0.2091 & 0.1716 & 0.1795 & 0.6940 & 1 \\
\hline Portland, OR-WA & 0.1048 & 0.1406 & 0.1215 & 0.2387 & 0.0454 & 0.6509 & 2 \\
\hline Baltimore, MD & 0.0944 & 0.1151 & 0.1227 & 0.1941 & 0.0465 & 0.5727 & 3 \\
\hline Denver-Aurora, CO & 0.0944 & 0.0956 & 0.1340 & 0.1692 & 0.0740 & 0.5673 & 4 \\
\hline Las Vegas-Henderson, NV & 0.1033 & 0.1457 & 0.1045 & 0.1382 & 0.0434 & 0.5351 & 5 \\
\hline Pittsburgh, PA & 0.0868 & 0.1414 & 0.0592 & 0.1494 & 0.0436 & 0.4803 & 6 \\
\hline San Jose, CA & 0.0921 & 0.0798 & 0.1305 & 0.1051 & 0.0629 & 0.4704 & 7 \\
\hline Milwaukee, WI & 0.1003 & 0.0971 & 0.0625 & 0.1272 & 0.0415 & 0.4285 & 8 \\
\hline Cleveland, OH & 0.0974 & 0.0974 & 0.0505 & 0.1112 & 0.0348 & 0.3913 & 9 \\
\hline Sacramento, CA & 0.0858 & 0.0898 & 0.0674 & 0.0742 & 0.0549 & 0.3720 & 10 \\
\hline San Antonio, TX & 0.0914 & 0.0387 & 0.0848 & 0.1057 & 0.0476 & 0.3682 & 11 \\
\hline St. Louis, MO-IL & 0.0971 & 0.0725 & 0.0598 & 0.0918 & 0.0348 & 0.3560 & 12 \\
\hline Austin, TX & 0.0845 & 0.0518 & 0.0583 & 0.1058 & 0.0247 & 0.3249 & 13 \\
\hline Orlando, FL & 0.0826 & 0.0545 & 0.0663 & 0.0782 & 0.0327 & 0.3142 & 14 \\
\hline Riverside-San Bernardino, CA & 0.0804 & 0.0524 & 0.0649 & 0.0528 & 0.0637 & 0.3142 & 15 \\
\hline Providence, RI-MA & 0.0816 & 0.0686 & 0.0465 & 0.0720 & 0.0412 & 0.3100 & 16 \\
\hline Charlotte, NC-SC & 0.0816 & 0.0651 & 0.0416 & 0.0925 & 0.0220 & 0.3028 & 17 \\
\hline
\end{tabular}


TABLE 4 (CONT'D). Analytical Results for Group B

\begin{tabular}{|l|c|c|c|c|c|c|c|}
\multicolumn{1}{|c|}{ UZA } & $\begin{array}{c}\text { VOMS/ } \\
\text { UPT }\end{array}$ & $\begin{array}{c}\text { FRE/ } \\
\text { VRM }\end{array}$ & $\begin{array}{c}\text { VRM/ } \\
\text { LandArea }\end{array}$ & UPT/POP & $\begin{array}{c}\text { TWM/ } \\
\text { LandArea }\end{array}$ & Synthesis & Ranking \\
\hline Columbus, OH & 0.0818 & 0.0664 & 0.0447 & 0.0547 & 0.0375 & 0.2851 & 18 \\
\hline Cincinnati, OH-KY-IN & 0.0666 & 0.1009 & 0.0331 & 0.0514 & 0.0279 & 0.2798 & 19 \\
\hline San Juan, PR & 0.0230 & 0.0781 & 0.0574 & 0.1025 & 0.0090 & 0.2700 & 20 \\
\hline Tampa-St. Petersburg, FL & 0.0784 & 0.0615 & 0.0396 & 0.0501 & 0.0309 & 0.2607 & 21 \\
\hline Virginia Beach, VA & 0.0800 & 0.0521 & 0.0432 & 0.0517 & 0.0304 & 0.2574 & 22 \\
\hline Jacksonville, FL & 0.0858 & 0.0432 & 0.0384 & 0.0471 & 0.0263 & 0.2408 & 23 \\
\hline Memphis, TN-MS-AR & 0.0889 & 0.0636 & 0.0239 & 0.0390 & 0.0226 & 0.2381 & 24 \\
\hline Kansas City, MO-KS & 0.0696 & 0.0449 & 0.0341 & 0.0449 & 0.0251 & 0.2185 & 25 \\
\hline Indianapolis, IN & 0.0739 & 0.0533 & 0.0230 & 0.0285 & 0.0131 & 0.1918 & 26 \\
\hline
\end{tabular}

TABLE 5.

Groups C-F Composite Ranking

\begin{tabular}{|c|c|c|c|c|}
\hline \multicolumn{3}{|c|}{ Top 10} & \multicolumn{2}{|l|}{ Bottom 10} \\
\hline Group & UZA & Rank & UZA & Rank \\
\hline \multirow{10}{*}{ C } & Urban Honolulu, $\mathrm{HI}$ & 1 & Baton Rouge, LA & 27 \\
\hline & Buffalo, NY & 2 & Allentown, PA-NJ & 28 \\
\hline & Albany-Schenectady, NY & 3 & Richmond, VA & 29 \\
\hline & Rochester, NY & 4 & Columbia, SC & 30 \\
\hline & Albuquerque, NM & 5 & Raleigh, NC & 31 \\
\hline & New Orleans, LA & 6 & Birmingham, AL & 32 \\
\hline & Fresno, CA & 7 & Toledo, OH-MI & 33 \\
\hline & Tucson, AZ & 8 & Colorado Springs, CO & 34 \\
\hline & Bakersfield, CA & 9 & Knoxville, TN & 35 \\
\hline & Louisville/Jefferson County, KY-IN & 10 & Mission Viejo-San Clemente, CA & 36 \\
\hline \multirow{10}{*}{ D } & Durham, NC & 1 & Greenville, SC & 53 \\
\hline & Anchorage, AK & 2 & Montgomery, AL & 54 \\
\hline & Stockton, CA & 3 & Asheville, NC & 55 \\
\hline & Madison, WI & 4 & Mobile, AL & 56 \\
\hline & Ann Arbor, MI & 5 & Youngstown, OH-PA & 57 \\
\hline & Spokane, WA & 6 & Wichita, KS & 58 \\
\hline & Lansing, MI & 7 & Augusta-Richmond County, GA-SC & 59 \\
\hline & Syracuse, NY & 8 & Jackson, MS & 60 \\
\hline & Oxnard, CA & 9 & Huntsville, AL & 61 \\
\hline & Flint, MI & 10 & Port St. Lucie, FL & 62 \\
\hline
\end{tabular}


TABLE 5. (CONT'D.) Groups C-F Composite Ranking

\begin{tabular}{|c|c|c|c|c|}
\hline \multicolumn{3}{|c|}{ Top 10} & \multicolumn{2}{|l|}{ Bottom 10} \\
\hline Group & UZA & Rank & UZA & Rank \\
\hline \multirow{10}{*}{$\mathrm{E}$} & Athens-Clarke County, GA & 1 & Elkhart, IN-MI & 53 \\
\hline & Seaside-Monterey, CA & 2 & Killeen, TX & 54 \\
\hline & Champaign, IL & 3 & Amarillo, TX & 55 \\
\hline & Gainesville, FL & 4 & Aberdeen-Bel Air North, MD & 56 \\
\hline & Santa Barbara, CA & 5 & Winter Haven, FL & 57 \\
\hline & lowa City, IA & 6 & Leesburg-Eustis-Tavares, FL & 58 \\
\hline & Santa Cruz, CA & 7 & Texas City, TX & 59 \\
\hline & Eugene, OR & 8 & Gainesville, GA & 60 \\
\hline & Bellingham, WA & 9 & Fort Walton Beach-Navarre-Wright, FL & 61 \\
\hline & Portland, ME & 10 & Hickory, NC & 62 \\
\hline \multirow{10}{*}{$F$} & Ames, IA & 1 & Uniontown-Connellsville, PA & 51 \\
\hline & State College, PA & 2 & Salisbury, MD-DE & 52 \\
\hline & Ithaca, NY & 3 & Longview, WA-OR & 53 \\
\hline & Kahului, $\mathrm{HI}$ & 4 & Lodi, CA & 54 \\
\hline & Morgantown, WV & 5 & Kokomo, IN & 55 \\
\hline & Blacksburg, VA & 6 & Carbondale, IL & 56 \\
\hline & Davis, CA & 7 & Victoria, TX & 57 \\
\hline & Portsmouth, NH-ME & 8 & Sherman, TX & 58 \\
\hline & Harrisonburg, VA & 9 & San Angelo, TX & 59 \\
\hline & Lawrence, KS & 10 & Elizabethtown-Radcliff, KY & 60 \\
\hline
\end{tabular}

In this methodology, when all members of a peer group all have similar outcomes on a performance measure, it will receive low weight in the ranking methodology. As the performance varies more widely, the weight assigned to that performance measure will increase. Thus, the algorithm puts the highest weight on the criteria that tend to more sharply distinguish higher-performing and lower-performing members of the peer group.

Table 5 identifies the weighting criteria that the model assigned to each of the five performance measures for each of the six peer groups in the composite rankings. The table also highlights the factor that was most influential in driving the rankings of each peer group. For example, among the Peer Group C cities (500k-1M population), Route Coverage (transitway miles per square mile of land area) had the strongest effect on the rankings, whereas among the Group F cities (50k-100k population), the model assigned the greatest weight to Revenue per Vehicle Mile. This does not mean that transit managers in Group F urbanized areas are unconcerned about route coverage. Instead, it suggests that Group F communities might have relatively similar land use patterns or perhaps that decisionmakers in Group F communities have fairly similar viewpoints about how intensive the transit route coverage should be.

Although the NTM data show that the amount of revenue earned per vehicle-mile differs greatly in Group F cities, the reasons for these differences are not obvious. 
Nevertheless, the rankings provide a starting point for probing possible explanations. For example, upon inspection, it is clear that the cities ranked near the top of the Group F list are mainly university towns such as Ames, IA (lowa State University), State College, PA (Penn State University), and Ithaca, NY (Cornell University). Older industrial cities and cities with low/lenient fare policies tend to be toward the lower end of the list.

TABLE 6.

Weights Assigned by Model to Each Performance Criterion

\begin{tabular}{|c|c|c|c|c|c|}
\hline \multirow{2}{*}{$\begin{array}{c}\text { Peer } \\
\text { Group }\end{array}$} & $\begin{array}{c}\text { Fleet } \\
\text { Utilization }\end{array}$ & $\begin{array}{c}\text { Revenue per } \\
\text { Vehicle-Mile }\end{array}$ & $\begin{array}{c}\text { Operational } \\
\text { Intensity }\end{array}$ & $\begin{array}{c}\text { Ridership } \\
\text { Intensity }\end{array}$ & $\begin{array}{c}\text { Route } \\
\text { Coverage }\end{array}$ \\
\cline { 2 - 6 } & UPT/VOMS & FRE/VRM & VRM/Area & UPT/POP & TWM/Area \\
\hline A & 0.14 & 0.17 & $\mathbf{0 . 3 0}$ & 0.20 & 0.19 \\
\hline B & 0.13 & 0.18 & 0.23 & $\mathbf{0 . 2 7}$ & 0.19 \\
\hline C & 0.21 & 0.17 & 0.15 & 0.17 & $\mathbf{0 . 3 1}$ \\
\hline D & 0.14 & 0.14 & $\mathbf{0 . 2 8}$ & 0.27 & 0.16 \\
\hline E & 0.16 & 0.23 & 0.22 & $\mathbf{0 . 2 6}$ & 0.12 \\
\hline F & 0.17 & $\mathbf{0 . 2 9}$ & 0.14 & 0.22 & 0.18 \\
\hline
\end{tabular}

Although the methodology requires discretion regarding the selection of performance measures and the definition of peer groups, it does not depend on any a priori human judgement to set weighting criteria. As a result, it can serve as a starting point for developing correlations between transit operational characteristics and the resulting performance outputs. For example, there is a longstanding debate about the extent to which rail and bus rapid transit (BRT) serve as flagship services that help attract discretionary riders. Figure 3 explores this notion quantitatively by comparing the composite rankings of the Group A cities with the proportion of their transitway mileage that is comprised of BRT + rail. This graph suggests that there is some relationship between $B R T+$ rail intensiveness and the overall performance of the system, but it is not the sole determinant of performance outcomes. More specifically, a linear relationship between BRT + rail intensiveness and composite score appears to exist for about a dozen of the 16 urbanized areas in Group A, but the three most railintensive conurbations (Boston, Chicago, Philadelphia) are clustered on the right side of the chart, with composite scores only near the middle of the pack. Dallas is also an outlier. 


\section{Proportion of Transit-Way Miles that are BRT or Rail vs Composite Fuzzy AHP Score}

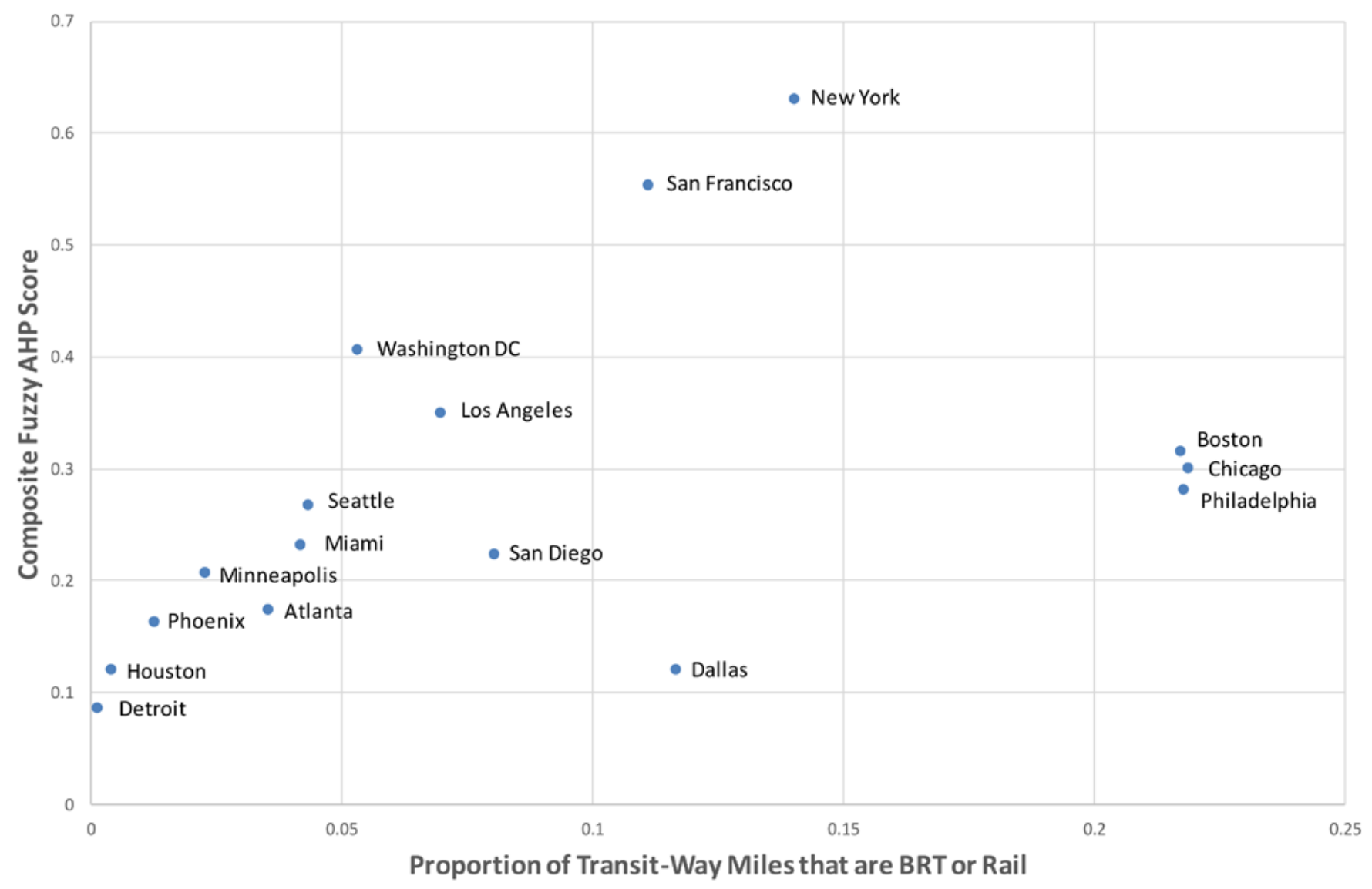

FIGURE 3. Proportion of transitway miles on BRT on rail vs. composite score for 16 Group A cities

The composite rankings potentially could be used to identify other types of performance outliers. For example, Salt Lake City, UT; Seaside- Monterey, CA; and Kahului, $\mathrm{HI}$ all scored near the top of their respective lists because they operate considerably more vehicle revenue-miles per square mile of land area than their peers. Since the NTM data set attributes all service to the largest UZA served by each agency, this potentially indicates that compared to their peers, these UZAs offer more service connecting to nearby rural or small urban areas. Conversely, communities that scored low due to low revenue per vehicle-mile are potential candidates for intensified marketing programs, or might simply have lower fares than their peers.

\section{Comparison of "Efficiency" and "Effectiveness"}

In addition to the overall performance analysis presented in the preceding section, the results of the fuzzy AHP process can be used to compare the extent to which there 
are trade-offs between the business efficiency performance measures and operational effectiveness measures. As noted in the literature review, this has been debated in the academic literature, with some authors taking the view that higher efficiency comes at the price of lower effectiveness and other studies supporting the view that the two are somewhat independent. Our results suggest that both assertions are partially justifiedit depends on which urban areas are included in the sample.

The efficiency and effectiveness scores for each of the 294 UZAs are plotted in Figure 4, with Business Efficiency on the horizontal axis and Operational Effectiveness on the vertical axis. Dots of various colors identify the members of each peer group, and regression lines are plotted for each of the six groups. The slope of these regression lines provides an indication of the tendency for the cities in each group to prioritize efficiency or effectiveness: a more vertical slope indicates an emphasis on effectiveness, and a slope closer to the horizontal indicates that greater emphasis has been put on efficiency.

The Comparison of Efficiency and Effectiveness

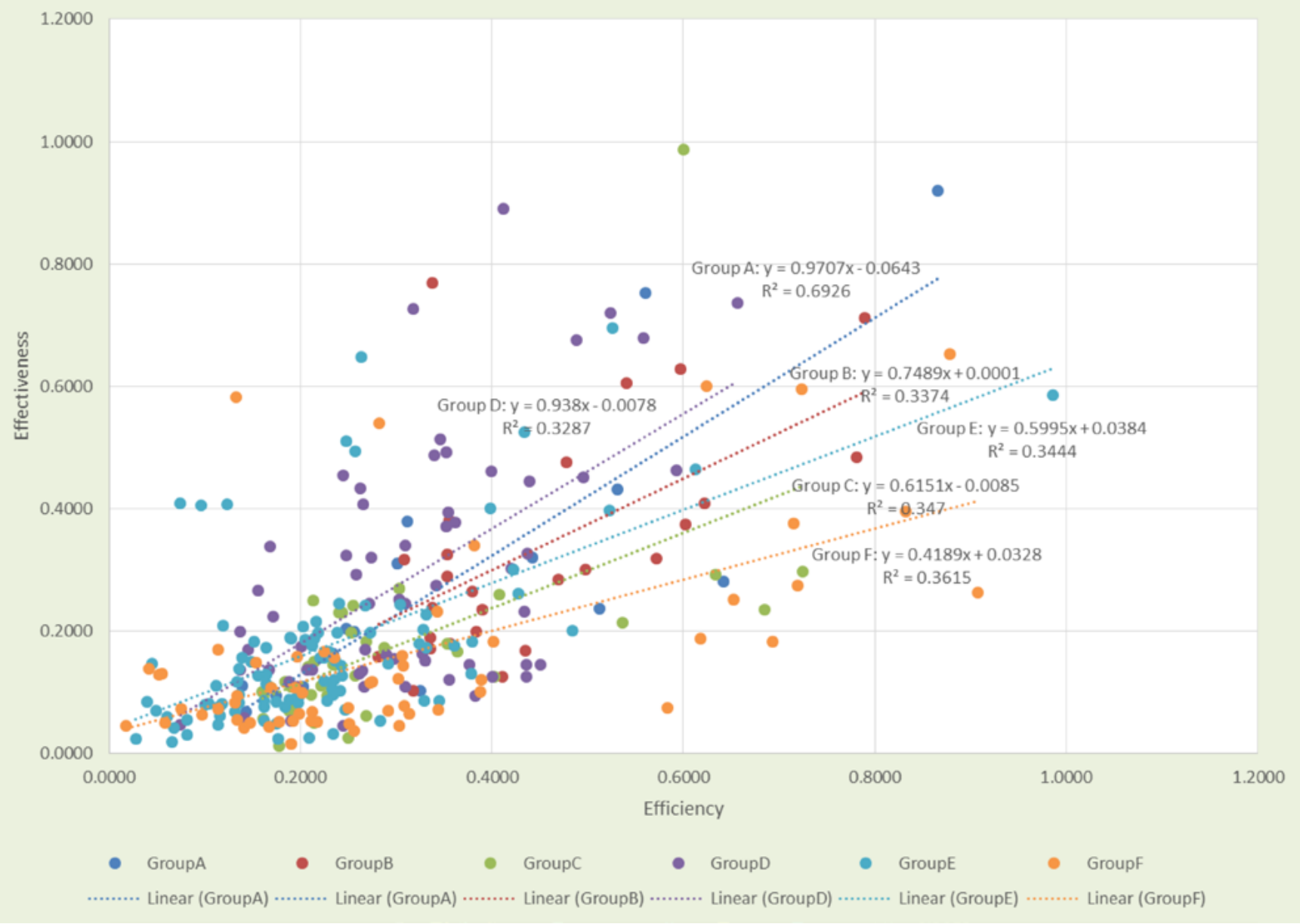

FIGURE 4. Scatter plot of business efficiency vs. operational effectiveness 
The analysis suggests that the urbanized areas in Peer Groups $A$ and D differ from the other four peer groups. Many of the UZAs in Group A score quite well on both efficiency and effectiveness measures, i.e., the data points tend to fall toward the upper right corner of the graph. Exogenous factors probably explain these results. For example, most Group A conurbations have relatively high population and employment densities, perhaps providing ridership sufficient to support extending the geographical extent of the systems well into the suburbs. Transit ridership in Group A cities is also influenced by traffic congestion (with the exception of Philadelphia and San Diego, automobile commuters in all Group A cities experience traffic delays exceeding 50 hours annually according to the $2015 \mathrm{TTI} /$ Inrix mobility scorecard [Schrank et al. 2015]). In addition, several Group A cities have land use patterns that are relatively favorable to transit; New York, Philadelphia, Boston, and Chicago are examples of metro areas whose "main line" suburbs developed around commuter rail stations in the late 19th and early 20th centuries (Jackson 1985). Further research potentially could elaborate the relationships between land use patterns and the transit performance for these cities.

Group $\mathrm{D}$ includes a number of university towns. With a base of by student and university employee ridership, it appears that these communities are able to provide relatively comprehensive geographical coverage.

With the exception of some university towns and other unusual cases, the cities in Groups B, C, E, and F tend to have transit systems that appear to be more focused on efficiency than on operational effectiveness. This perhaps reflects the fiscal realities of these transit systems. When faced with budgetary challenges, transit planners often respond by cutting off-peak services (Nelson Nygard Consulting Associates 2009), trimming less-productive routes (Bizjak 2016), raising fares (Rutti 2016), and finding ways to use personnel and equipment as efficiently as the circumstances allow. Many of the cities in these groups also have low-density land use patterns and relatively uncongested traffic, and some lack supporting infrastructure such as sidewalks connecting transit stops to traffic generators-conditions that can make it difficult to attract discretionary riders or justify service expansions.

\section{Conclusions and Opportunities}

"Good performance" for transit systems is a stew with many ingredients. Focusing on a single performance measure (such as farebox recovery ratio) is problematic because transit systems serve a multitude of constituencies and policy objectives. Policymakers do not always agree about the relative importance of each objective, and experts might differ about how to weight the performance measures that correspond to the policy goals. This preliminary exploration suggests that the fuzzy AHP method could be useful in establishing an objective basis for comparing the performance of different systems, without the need to develop a consensus on which policy objectives are the highest priority. The methodology also provides tools that transit systems could use to compare themselves to peer groups based on readily-available data. 
The analysis identified some strengths and limitations of the recently-developed NTM data set. Although the NTM currently contains only a limited set of transit performance measures, its spatial aggregation level (UZAs) is not readily-available in most other data sources. An important characteristic of the NTM is that each transit agency's performance data are associated only with the largest UZA it serves. Although this avoids double-counting when measures are summed on a national, regional, or statewide basis, when viewed from the perspective of individual communities, it tends to understate the amount of transit service provided in smaller UZAs. As a result, the NTM in its current form is perhaps best-suited to identifying well-performing UZAs and is less reliable as an indicator of poorly-performing UZAs.

The methodology presented in this paper could be enhanced by adding additional performance measures that were not available in the NTM data set. As the number of metrics increases, greater caution will be necessary to minimize the effects of correlations between the analytical metrics; for example, as the number of transitway miles increases, it is likely that the number of vehicle revenue miles also will increase. Further investigation with additional metrics also could help determine which performance metrics produce the most stable and consistent analytical results. For example, expansion of the methodology could help analysts avoid situations where the rank order is unduly influenced by the addition or omission of data for a small number of peer group members.

In future research, many other relationships could be explored using the composite scores. For example, university towns and urban areas with high land values (such as New York City, San Francisco, and Honolulu) tend to score well, perhaps because they have high relatively low car ownership rates compared to their peers. Similarly, there might be a relationship between system performance and the overall economic situation in each community; underlying factors could explored by combining this ranking system with UZA-level economic data.

It might also be worthwhile to investigate applications of the fuzzy AHP methodology for comparisons of the performance of internal accounting cost centers within a transit system, such as individual rail lines or bus routes. Potentially, such investigations would assist agencies in identifying opportunities to strengthen overall system performance by pinpointing lines or routes that are not performing as well as their peers.

\section{References}

Abreha, D. A. 2007. "Analysing Public Transport Performance using Efficiency Measures and Spatial Analysis: The Case Study of Addis Ababa, Ethiopia." Master's thesis, International Institute for Geo-information Science and Earth Observation, Enschede.

Andersen, P., and N. P. Christian. 1993. "A Procedure for Ranking Efficient Units in Data Envelopment Analysis." Management Science, 39(10): 1261-1264.

Badami, M. G., and M. Haider. 2007. "An Analysis of Public Bus Transit Performance in Indian Cities." Transportation Research Part A: Policy and Practice, 41: 961-981. 
Barnum, D. T., S. Tandon, and S. McNeil, 2008. "Comparing the Performance of Urban Transit Bus Routes after Adjusting for the Environment, Using Data Envelopment Analysis." Great Cities Institute, University of Illinois at Chicago.

Bizjak, T. 2016. "Light-Rail Green Line May Shut in Sacramento to Save Money." Sacramento Bee, May 20. http://www.sacbee.com/news/local/transportation/ article78954437.html.

Charnes, A. C., W. W. Cooper, and E. L. Rhodes. 1978. "Measuring the Efficiency of Decision Making Units." European Journal of Operational Research, 2: 429-444.

Chu, X., G. J. Fielding, and B. W. Lamar. 1992. "Measuring Transit Performance Using Data Envelopment Analysis." Transportation Research Part A: Policy and Practice, 26(3): 223-230.

Cook, W. D., and L. M. Seiford. 2009. “Data Envelopment Analysis (DEA)-Thirty Years On." European Journal of Operational Research, 192(1): 1-17.

Eboli, L., and G. Mazzulla. 2011. "A Methodology for Evaluating Transit Service Quality Based on Subjective and Objective Measures from the Passenger's Point of View." Transport Policy, 18: 172-181.

Fan, Y. 2015. “National Transit Map—United States: A Global Transit Innovations Data System." University of Minnesota.

Fielding, G. J., R. E. Glauthier, and C. A. Lave. 1978. “Performance Indicators for Transit Management." Transportation, 7(4): 365-379.

Fielding, G. J., T. T. Babitsky, and M. E. Brenner. 1985. “Performance Evaluation for Bus Transit." Transportation Research Part A: General, 19(1): 73-82.

Fielding, G. J. 1992. "Transit Performance Evaluation in the US." Transportation Research Part A: Policy and Practice, 26(6): 483-491.

Griffis, Stanley E., Martha Cooper, Thomas J. Goldsby, and David J. Closs. 2004/ "Performance Measurement: Measure Selection Based upon Firm Goals and Information Reporting Needs," Journal of Business Logistics, 25(2): 95-118.

Hanaoka, P., and P. Kunadhamraks. 2009. "Multiple Criteria and Fuzzy Based Evaluation of Logistics Performance for Intermodal Transportation." Journal of Advance Transportation, 43(2): 123-153.

Jackson, K. T. 1985. Crabgrass Frontier: The Suburbanization of the United States. London: Oxford University Press.

Karlaftis, M. G. 2004. "A DEA Approach for Evaluating the Efficiency and Effectiveness of Urban Transit Systems." European Journal of Operational Research, 152(2): 354-364.

Kittelson \& Associates. Federal Transit Administration, Transit Cooperative Research Program, and Transit Development Corporation. 2003. Transit Capacity and Quality of Service Manual, Vol. 100. Transportation Research Board.

Korostelev, A., L. Simar, and A. B. Tsybakov, 1995. "Efficient Estimation of Monotone Boundaries." Annals of Statistics, 23: 476-489. 
Kurtzleben, D. 2011. "10 Best Cities for Public Transportation." US News \& World Report. http://www.usnews.com/news/articles/2011/02/08/10-best-cities-for-publictransportation.

Lao, Y., and L. Liu, L. 2009. "Performance Evaluation of Bus Lines with Data Envelopment Analysis and Geographic Information Systems." Computers Environment and Urban Systems, 33: 247-255.

Li, X., Y. Liu, D. Liu, and Z. Gao. 2015. "Multidimensional Assessment of Developing an Urban Public Transit Metropolis in China." Journal of Urban Planning and Development, 142(3): 04015021.

Nathanail, E. 2008. "Measuring the Quality of Service for Passengers on the Hellenic Railways." Transportation Research Part A, 42: 48-66.

Neff, J., and M. Dickens. 2013. Public Transportation Fact Book. American Public Transportation Association, Washington, DC.

Nelson Nygard Consulting Associates. 2009. "Stranded at the Station: The Impact of the Financial Crisis in Public Transportation. http://www.environmentalcouncil.org/ mecReports/Stranded-at-the-station.pdf.

Rutti, R. 2016. "RTA Approves Fare Increases, Service Cuts to Help Erase \$7 Million Budget Gap." Crain's Cleveland Business, June 7. http://www.crainscleveland.com/ article/20160607/NEWS/160609845/rta-approves-fare-increases-service-cuts-tohelp-erase-7-million.

Ryus, P., M. Connor, S. Corbett, A. Rodenstein, L. Wargeling, L. Ferreira, Y. Nakanishi, and K. Blume. 2003. "Guidebook for Developing A Transit Performance-Measurement System." TCRP Report 88.

Ryus, P. 2010. "A Methodology for Performance Measurement and Peer Comparison in the Public Transportation Industry, Vol. 141." Transportation Research Board.

Saaty, T. L. 1980. The Analytic Hierarchy Process. New York: McGraw-Hill.

Schrank, D.. W. Eseele, T. Lomax, and J. Bak, 2015. “Urban Mobility Scorecard.” Texas A\&M Transportation Institute and Inrix, Inc. http://d2dt|5nnlpfrOr.cloudfront.net/ tti.tamu.edu/documents/mobility-scorecard-2015.pdf.

Sheth, C., K. Triantis, and D. Teodorovic. 2007. "Performance Evaluation of Bus Routes: A Provider and Passenger Perspective." Transportation Research Part E, 43: 453-478.

Simar, L., and P. Wilson. 1998. "Sensitivity Analysis of Efficiency Scores: How to Bootstrap in Non-Parametric Frontier Models." Management Science, 44: 49-61.

Song, M. L., L. L. Zhang, W. Liu, and R. Fisher. 2013. “Bootstrap-DEA Analysis of BRICS' Energy Efficiency Based on Small Sample Data. Applied Energy, 112: 1049-1055.

Talley, W. K., and P. P. Anderson. 1981. Effectiveness and Efficiency in Transit Performance: A Theoretical Perspective." Transportation Research Part A: General, 15(6): 431-436. 
Transportation Research Board of the National Academies. 2003. Transit Capacity and Quality of Service Manual. Washington, DC.

Tyrinopoulos, Y., and C. Antoniou. 2008. "Public Transit User Satisfaction: Variability and pOlicy Implications." Transport Policy, 15: 260-272.

US Census Bureau. 2013. "2010 Census Urban Area Facts." http://www.census.gov/geo/ reference/ua/uafacts.html.

UITP (International Association of Public Transport). 2010. "Report on Statistical Indicators of Public Transport Performance in Sub-Saharan Africa." http://www. uitp.org.

Wang, Y. M., C. Parkan, and Y. Luo. 2008. A Linear Programming Method for Generating the Most Favorable Weights from a Pair Wise Comparison Matrix." Computers and Operations Research, 35 (12): 3918-3930.

Yeh, C-H., H. P. Deng, and Y-H. Chang. 2000. "Fuzzy Multi-Criteria Analysis for Performance Evaluation of Bus Companies." European Journal of Operational Research, 126(3): 459-473.

Yu, J., Y. Liu, G. L. Chang, W. J. Ma, and X. G. Yang. 2011. "Locating Urban Transit Hubs: A Multi-Criteria Model and Case Study in China." ASCE Journal of Transportation Engineering, 137(12): 944-952.

\section{About the Authors}

XIN LI, PH.D. (li44@uwm.edu) is a Post-Doctoral Researcher at the University of Wisconsin-Milwaukee.

Yingling FaN, PH.D. (yingling@umn.edu) is Associate Professor in the Urban and Regional Planning Program of the Humphrey School of Public Affairs at the University of Minnesota.

JoHN W. SHaW, P.E. (jwshaw@wisc.edu) is a Researcher at the University of Wisconsin-Madison.

YUNLEI QI (yunleiqi@umn.edu) is a Ph.D. student in the Urban and Regional Planning Program of the Humphrey School of Public Affairs at the University of Minnesota. 